\title{
Allergic reactions to the first COVID-19 vaccine: a potential role of Polyethylene glycol?
}

Natalija Novak ${ }^{1}$, Cezmi Akdis², and Beatriz Cabanillas ${ }^{1}$

${ }^{1}$ University of Bonn

${ }^{2}$ University of Zurich

December 11, 2020

\section{Hosted file}

Allergic reactions to the first COVID-19 vaccine (101220).pdf available at https://authorea. com/users/382412/articles/498310-allergic-reactions-to-the-first-covid-19-vaccine-apotential-role-of-polyethylene-glycol

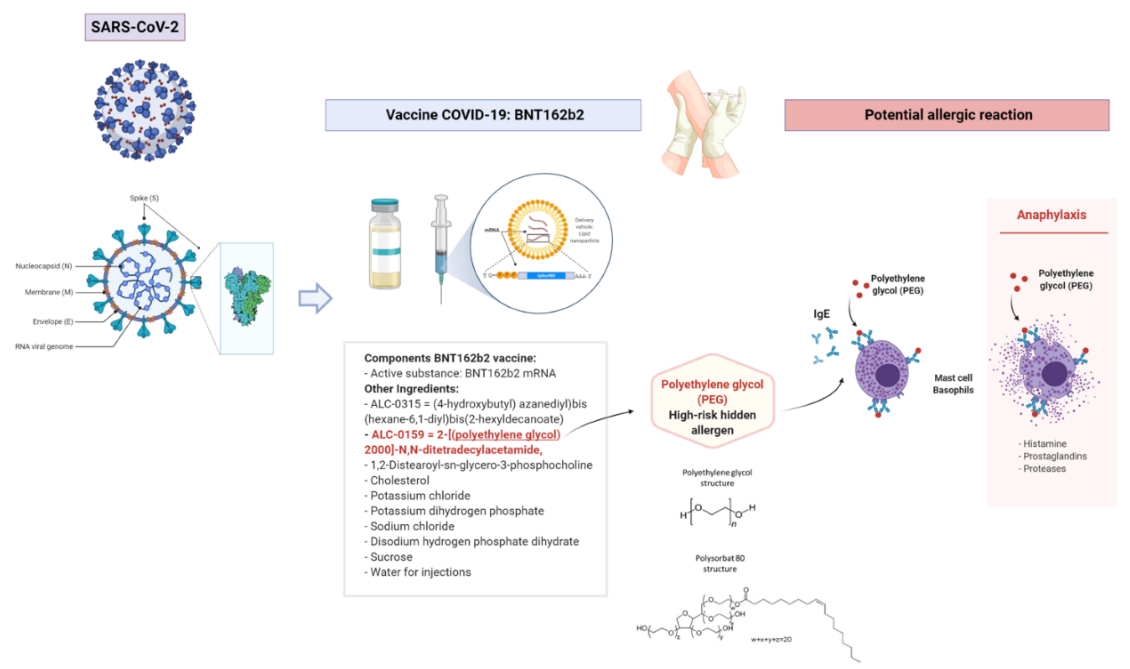

